\title{
Research on Path Selection of Digital Governance of Online Education
}

\author{
Yifei Gong*, Yue He, Daijun Xie, Jing Chen \\ College of Economic and Management, Southwest University, Chongqing, China \\ Email: ^gyifeieva@163.com
}

How to cite this paper: Gong, Y. F., He, Y., Xie, D. J., \& Chen, J. (2021). Research on Path Selection of Digital Governance of Online Education. Modern Economy, 12, 469-476.

https://doi.org/10.4236/me.2021.123024

Received: February 4, 2021

Accepted: March 7, 2021

Published: March 10, 2021

Copyright (อ 2021 by author(s) and Scientific Research Publishing Inc. This work is licensed under the Creative Commons Attribution International License (CC BY 4.0).

http://creativecommons.org/licenses/by/4.0/ (c) (i) Open Access

\begin{abstract}
In recent years, emerging technologies such as big data, blockchain, artificial intelligence, and cloud computing have matured. The integration of digital technology and online education promotes online education governance into the digital age. However, there are still some governance dilemmas in the digitalization process. How to solve the existing difficulties and promote the digital governance process of online education is the top priority for the development of online education. On the basis of clarifying the connotation of digital governance of online education, this paper explains the difficulties faced by online education in the digital age, and proposes the implementation path, including imperfect teaching platform and lack of supervision system, perfecting education evaluation model, establishing risk control and early warning mechanism.
\end{abstract}

\section{Keywords}

Online Education, Digital Governance, Path Selection

\section{Introduction}

\subsection{Research Background}

The Fifth Plenary Session of the $19^{\text {th }}$ Central Committee of the Party proposed that during the " $13^{\text {th }}$ Five-Year Plan" period, major breakthroughs were made in comprehensively deepening reforms, and the modernization of the national governance system and governance capabilities was accelerated. It also proposed that during the " $14^{\text {th }}$ Five-Year Plan" period, we should also actively promote the modernization of the national governance system and governance capabilities. In response to the party's call, we need to speed up the pace of governance, actively shape new governance concepts, strive to improve governance capabilities, 
and form a governance system that suits my country's national conditions. In recent years, my country's digital technology industry has developed rapidly. Emerging science and technology represented by 5G, big data, artificial intelligence, etc. began to appear in various industries and fields, significantly promoting the rapid and high-quality development of my country's economy. Education is an eternal topic for mankind. Due to the outbreak of the epidemic in 2020 , people's demand for online education has surged. The continuous promotion of online education by colleges and universities has promoted the continuous collision and integration of digital technology and the education industry. This is not only conducive to promoting my country's education to enter the stage of digital governance, but also making a positive contribution to the modernization of the national governance system and governance capabilities. Therefore, how to use big data, artificial intelligence and other digital technologies to enhance the digital governance capabilities of online education and accelerate the modernization of my country's governance capabilities has become an important proposition of the times. This article mainly takes online education as the main body, with the background of the digital age, studies the digital governance path of online education, and then puts forward the problems of imperfect teaching platform, lack of supervision system, imperfect education evaluation system and the data and information security risks. This puts forward the corresponding governance path.

\subsection{Significance}

In the overall plan for the development of education, supporting the online education system and optimizing online education resources have always been the path of policy adherence. As a product of the integration of digital technology and the education industry, online education has fundamentally changed the way to acquire knowledge. The space and location of teaching have changed, leading to more diversified channels for absorbing knowledge. This not only updates the education model, but also improves the education system and achieves education equity. The research on this subject has revealed the current dilemmas in the digital governance of online education in my country, and proposed governance paths such as improving the education platform, optimizing the education evaluation system, establishing regulatory governance and early warning mechanisms, thereby enhancing the ability of education governance and advancing the national governance system contribute to the modernization of governance and governance capabilities, laying the foundation for the overall goal of deepening reform.

\section{Connotation of Online Education Digital Governance}

\subsection{Connotation of Digital Governance}

With the emergence of high technology such as big data and artificial intelligence, keywords such as "digitalization" and "intelligence" have begun to enter 
the public's field of vision. While innovating the governance models, the governance system was optimized. Since then, theories related to digital governance have begun to expand and has become one of the hot topics discussed and studied by Chinese scholars, and my country has gradually formed a digital governance path in line with my country's national conditions (Chen, Liu, \& Gao, 2020). An analysis of digital governance from the perspective of management finds that digital governance is essentially a management method. Through the use of a series of high and new technologies such as big data, 5G, cloud computing, artificial intelligence, and blockchain, it can quantify management objects and management behaviors, so as to achieve the purpose of making public management activities more efficient and faster, and communicating the information of both parties. Digital governance rebuilds a new communication and management model between people and society, promotes the scientific and efficient social governance, and better promote economic and social development.

\subsection{Motivation for Digital Transformation of Online Education}

Affected by the new crown epidemic in 2020, emerging technologies such as big data, blockchain, and artificial intelligence have entered our study, work and life more significantly, such as online retests for postgraduate entrance examinations, health codes under the new crown epidemic, and online office. As the forward position for the generation and application of new technologies and new ideas, the education industry has applied digital technology to online education activities in recent years. The most representative of these is that some universities and off-campus training institutions have joined MOOCs. But there are still many organizations that only use modern information technology as a tool or practical existence (Luo \& Yang, 2020). In this context, the traditional online education system is powerless in the face of a huge amount of data and information. Therefore, online education institutions must reform and innovate management methods to meet the needs of teaching and daily management. Digital governance is produced in the context of the rapid development of information technology, and it is also the core of the modern governance of online education.

\subsection{Connotation of Digital Governance of Online Education}

Digital governance of online education is the integration of digital governance and online education governance to form a new ecological environment in the education field (Feng, 2021). The development of online education under digital governance has the following characteristics: The first is digitization. Digital technology can be used to simplify the complex, reflect the phenomenon of education with numbers, and intuitively discover problems in the governance process of online education, and optimize governance capabilities. The second is intelligence, combining science and technology such as the Internet with education models can break through the limitations of previous education governance and 
optimize the quality of education. The third is integration. Digital innovation realizes symmetry of information, makes information transparent and open, and facilitates two-way communication. It promotes the coordinated development of society, online education institutions, and third-party education. Educational governance has always been an indispensable part of my country's modernization of governance capabilities and governance system. As a new ecology formed by the combination of the Internet and traditional education, online education has new opportunities in the governance process with the advent of digitalization. This has not only promoted education reform, but also enhanced my country's governance capabilities.

\section{The Dilemma of Online Education Governance in the Digital Age}

\subsection{Incomplete Teaching Platform and Lack of Supervision System}

Digital governance has indeed played a positive role in online education governance, but the current shortcomings cannot be ignored (Lan \& Chen, 2020). First of all, many online education institutions do not have a clear positioning for digital governance, but blindly follow the trend, and are prone to problems such as focusing on construction and neglecting applications. For example, current online education platforms in my country focus on teachers' design of courseware content, ignoring students' participation in the learning process and the innovation of learning models have led to the same online education format. Therefore, traditional teaching methods and thinking still exist in online education and insufficient governance capabilities lead to online Education cannot meet the transformation of educational models in the digital context. Secondly, online education requires a good network environment. If too many people are online at the same time, it is easy to cause network traffic jam and poor teaching effects. Finally, the regulation of online education governance is an indispensable link in the digitalization process. At present, there is a lack of relevant legal systems and no mandatory clauses, which leads to the failure of the supervision effect to meet expectations. It can be seen that in the journey of online education governance to meet the arrival of the digital age, problems such as imperfect teaching platforms and insufficient governance capabilities have yet to be resolved.

\subsection{The Education Evaluation System is not Sound}

Educational evaluation mainly includes the evaluation of teachers' talent training ability, the evaluation of students' academic performance, and the evaluation of scientific research results, which is an evaluation of the quality of teaching work. Digital technology promotes the transformation of online education methods and educational models. Traditional online education simply shifts from offline to online, and its evaluation is usually based on human subjective evaluation, and it is impossible to objectively and comprehensively evaluate the entire education link. First of all, in the evaluation of students' academic performance, 
most of the evaluations of relevant institutions on students' learning are determined by test scores. They cannot track and feedback the entire learning process of students, and cannot accurately control the learning ability of students. Secondly, in terms of teacher talent training ability and scientific research achievements evaluation, the existing evaluation system is too one-sided and thin, and it is impossible to quantitatively evaluate talent training ability and scientific research achievements (Zhao \& Duan, 2020). Therefore, how to ensure that teachers' ability to train students does not decline, how to scientifically measure scientific research results, break through the shackles of traditional online education evaluation systems, and promote fair and objective educational evaluation results are important issues facing digital governance.

\subsection{Data Information Security Risk}

In the process of digital governance of online education, governance entities can automatically collect and master a large amount of data, which includes not only information related to teaching and learning, but also the identity information and privacy information (Lei, 2019). One of the major characteristics of online education digital governance construction is integration, which requires various institutions to share data. In the process of online education digital governance, the main source of relevant data is students who are just beginning to contact the society. They are extremely dependent on the Internet. At the same time, they do not have the corresponding information literacy to protect their own privacy, which makes the digital governance of online education have a greater risk in protecting information security. In addition, with the rapid growth of malware attacks, technical risks continue to increase too. Among the top ten IT issues that promote the digital transformation of higher education, information security has been ranked first for several years in the top ten information technology issues. Online education is no exception. The risk of personal information leakage is gradually increasing, making information security issues The solution becomes more urgent (Lan et al., 2020).

\section{Digital Governance Path for Online Education}

\subsection{Improve the Education Platform and Establish a Supervision Mechanism}

In the digital age, the governance of the higher education system and online education have changed one after another, and the reform of education governance has become scientific and professional. First of all, online education platforms should not only focus on the design of learning content, but also make full use of science and technology such as blockchain to achieve diversification of teaching modes, introduce virtual classrooms to form teacher-student interaction and cultivate innovative talents. In addition, 5G technology should be promoted as soon as possible, So as to provide a smooth network environment for online education. Secondly, in order to further strengthen the concept of educa- 
tion equity, online education platforms must not only be concentrated in cities, but also be derived from remote areas such as rural areas to improve the information literacy of rural teachers and students, optimize the allocation of educational resources, and introduce excellent teacher resources. Finally, integrate external stakeholders into online education governance, use blockchain data to achieve cross-regional cooperation, examine online education governance from a new perspective, and form a new education governance system.

The process of online education governance also needs the supervision of social forces, and rules should be constructed to use power to regulate behavio $r$ (Shi \& Pan, 2019). First, formulate relevant policies for digital governance, create a macro atmosphere, and derive digital governance into online educational institutions; secondly, it is necessary to correctly guide the use of digital technology, regulate use behavior, and build and improve the security guarantee mechanism for digital governance; Some education laws and regulations add content related to the safe development of online education digital education governance.

\subsection{Improve Education Evaluation Model}

Another path for the digital governance of online education is to improve the education evaluation model. The first is the transformation of the evaluation mechanism of academic performance. Online education institutions can effectively combine big data, artificial intelligence, cloud computing and other digital technologies with student learning management systems to track and record the data in the entire learning process in real time to achieve an overall view control of learning effects. This can not only strengthen students' learning motivation and improve the quality of talent training, but also promote the evaluation mechanism of academic performance to become more scientific and objective (Chen, Liu, \& Gao, 2020).

In terms of the evaluation mechanism of teacher talent training ability, relevant institutions can make full use of digital technology to build an evaluation system that integrates teaching quality evaluation, and use data to reflect the results of education quality, which is more comparable and operable, and also improves the objectivity and scientific of education evaluation system, avoiding the preference of people as the subject of evaluation. At the same time, include teacher ability training links in the education evaluation system to encourage teachers and students to master the corresponding scientific and technical skills and practice them in the teaching process (Xie \& Yang, 2020). In terms of the evaluation mechanism of scientific research results, the emergence of emerging technologies has greatly improved the ability to mine and compare data, enriched the methods of checking data fraud and the review technology and review of academic misconduct, which is more conducive to promoting the strict and fair evaluation system of scientific research achievements in online education (Feng, 2021). In summary, online education institutions can build an online 
education digital governance platform with the assistance of digital technology talents, thereby improving and perfecting the education evaluation model, and accelerating the process of online education digital governance.

\subsection{Establish Risk Control and Early Warning Mechanism}

The sustainable development of online education digital governance requires information security. While thinking about the improvement path of education platforms and education evaluation mechanisms, we must also pay attention to information security issues. We can start from two aspects: risk control and risk early warning. In order to ensure information security and protect the privacy of teachers and students, the governing body of online education institutions should establish a risk control mechanism. First, create well-structured operating procedures without infringing privacy to ensure the safety of information collection, management and use (Lan et al., 2020). A set of well-structured operating procedures can limit certain improper behaviors, and also strengthen the protection of information to a certain extent. Second, increase the cost of risk control, and strengthen the strength of risk control, such as hiring special risks Control Specialist. Third, while sharing data information, install data monitoring tools to detect abnormal usage and data extraction in a timely manner. Fourth, online education institutions can use facial recognition technologies other than passwords to set access permissions to enhance the intensity of privacy protection.

Online education institutions can also establish risk early warning mechanisms, strengthen the restraint and prevention of information security risks, ensure information security and protect the privacy of teachers and students, and establish a risk early warning mechanism. The subjects involved are not limited to online education management personnel, but also include society and related government agencies. First, improve the top-level design, that is, improve Internet-related laws and regulations, and reduce the risk of information security accidents in the digitalization of online education. Second, train online education institution managers and end users so that they can use data correctly. Remind and warn them of the main points and importance of privacy protection.

\section{Conclusion}

The development of digital technology has had a huge impact on various industries and fields, and the close integration with online education has made online education gradually break away from the shackles of traditional development concepts and development models, accept the influence of more novel viewpoints, and gradually enter digitalization governance stage. Although there will be various challenges and negative impacts, online education institutions must move forward and provide a good guide and demonstration role for the education of flourishing development. This is not only the responsibility of the online education industry, but also the only way for the good development of the entire society. In this process, we must grasp the opportunities brought by digital 
technology, meet the challenges with an open and inclusive mind, strengthen the concept of digital governance, timely explore effective ways to promote the better integration of online education and digital technology, build a digital dynamic governance platform integrating digital technology and online education, strengthen risk control and assessment, provide suggestions for the establishment of an efficient and systematic online education digital governance mechanism, contribute to the effective promotion of the modernization of the national governance system and governance capabilities, and lay the foundation for the overall goal of deepening reform.

\section{Acknowledgements}

This article is supported by the 2020 Southwest University Continuing Education Research Project (SWU2008019) and the 2020 Southwest University Professional Core Curriculum Construction Project.

\section{Conflicts of Interest}

The authors declare no conflicts of interest regarding the publication of this paper.

\section{References}

Che, L., Liu, X., \& Gao, X. C. (2020). Realistic Challenges and Path Selection of Educational Governance from the Perspective of Artificial Intelligence. China Educational Science (Chinese and English), 3, No. 6.

Feng, X. X. (2021). Research on the Inner Logic, Core Essentials and Implementation Paths of Higher Education Digital Governance in my country. Heilongjiang Higher Education Research, 39, No. 1.

Lan, G. S., Zhang, Y., Guo, Q., Kong X. K., \& Wei, J. C. (2020). Promoting the Digital Transformation of Higher Education: Optimization, Sustainability and Innovation-Interpretation and Enlightenment of the "Top Ten IT Issues in 2020" Report. Open Education Research, 26, No. 5.

Lan, Y., \& Chen, Z. W. (2020). The Status Quo, Significance and Problems of Online Education in Colleges and Universities. Fortune Times, 11.

Lei, C. Z. (2019). Educational Reform in the Intelligent Era. Digital Teaching in Elementary and Secondary Schools, 9, 30-32.

Luo, Y. Y., \& Yang, X. F. (2020). On the "Digital Transformation" of Higher Education in the Information Age-and on How Disruptive Innovation from Traditional Universities to "Digital Universities" Is Possible. Beijing Education (Higher Education), 8.

Shi, H. X., \& Pan, C. (2019). A Preliminary Study on the Construction of a Harmonious Game Execution Model of Educational Policy. Modern Education Management, 10, 60-65.

Xie, Y., \& Yang X. F. (2020). The Digital Transformation of Higher Education Talent Training Model. Guangxi Social Sciences, 2.

Zhao, Z. X., \& Duan X. X. (2020). University Internal Governance from the Perspective of Artificial Intelligence: Logic, Dilemma and Path. Journal of Southwest University for Nationalities (Humanities and Social Sciences Edition), 41, No. 10. 